\title{
Risk Factors for Non-Ampullary Duodenal Adenocarcinoma: A Systematic Review
}

\author{
Yohei Yabuuchi $^{a}$ Masao Yoshida ${ }^{a}$ Naomi Kakushimab ${ }^{b}$ Motohiko Kato ${ }^{c}$ \\ Mikitaka Iguchi $^{d}$ Yorimasa Yamamoto $^{e}$ Kengo Kanetaka $^{f}$ Toshio Uraoka $^{g}$ \\ Mitsuhiro Fujishiro $^{b}$ Masayuki Sho ${ }^{\text {h }}$ on behalf of Japan Duodenal Cancer \\ Committee
}

aDivision of Endoscopy, Shizuoka Cancer Center, Shizuoka, Japan; bepartment of Gastroenterology and Hepatology, Nagoya University Graduate School of Medicine, Nagoya, Japan; 'Division of Research and Development for Minimally Invasive Treatment, Cancer Center, Keio University School of Medicine, Tokyo, Japan; dSecond Department of Internal Medicine, Wakayama Medical University, Wakayama, Japan; eDepartment of Gastroenterology, Showa University Fujigaoka Hospital, Kanagawa, Japan; 'Department of Surgery, Nagasaki University Graduate School of Biomedical Sciences, Nagasaki, Japan; 9Department of Gastroenterology and Hepatology, Gunma University Graduate School of Medicine, Maebashi, Japan; 'hepartment of Surgery, Nara Medical University, Nara, Japan

\section{Keywords}

Duodenal adenocarcinoma · Risk factors · Familial adenomatous polyposis $\cdot$ Systematic review

\begin{abstract}
Introduction: An increase in the incidence of duodenal adenocarcinoma has been recently reported. However, little is known about the risk factors for duodenal adenocarcinoma, which are important for screening purposes. We, therefore, aimed to conduct a systematic review to identify risk factors for non-ampullary duodenal adenocarcinoma. Methods: A medical literature search was performed using electronic databases, including PubMed, Cochrane Library, Japan Medical Abstracts Society, and Web of Science. Studies that assessed the association between dietary habits, lifestyle behaviors, comorbidities, and non-ampullary duodenal adenocarcinoma were extracted. The Newcastle-Ottawa Scale was used to assess the risk of bias in individual studies, and the Grading
\end{abstract}

of Recommendations, Assessment, Development, and Evaluations approach was used to assess the quality of evidence across studies included in this review. Results: Out of 1,244 screened articles, 10 were finally selected for qualitative synthesis. In the general population, no consistent risk factors were identified except for Helicobacter pylori positivity, which was considered a risk factor in 2 studies, but the quality of evidence was considered very low because of the high risk of bias. In patients with familial adenomatous polyposis (FAP), Spigelman stage IV at initial endoscopy was considered a consistent risk factor in 3 studies. Conclusions: There are currently limited data regarding risk factors for non-ampullary duodenal adenocarcinoma, and no conclusive risk factors were identified in the general population. However, in patients with FAP, Spigelman stage IV was identified as a consistent risk factor. Further studies are needed to improve diagnosis and support effective clinical management of this malignancy.

(c) 2021 The Author(s)

Published by S. Karger AG, Basel karger@karger.com

www.karger.com/ddi

Karger $\stackrel{\text { ! }}{=}$

BOPEN ACCESS
(C) 2021 The Author(s)

Published by S. Karger AG, Basel

This is an Open Access article licensed under the Creative Common Attribution-NonCommercial-4.0 International License (CC BY-NC) (http://www.karger.com/Services/OpenAccessLicense), applicable to the online version of the article only. Usage and distribution for commercial purposes requires written permission.
Correspondence to:

Yohei Yabuuchi, y.yabuuchi@scchr.jp 


\section{Introduction}

Cancer of the small intestine is rare and accounts for less than $5 \%$ of all gastrointestinal malignancies in the USA [1]. The duodenum is the most proximal portion of the small intestine and the most frequently involved segment [2]. The number of patients with duodenal adenocarcinoma has been gradually increasing [3-5]. Recently, we reported a higher incidence of duodenal cancer in Japan than rates in Western countries [6]. This indicates that this tumor is a potentially important area for research that may have immediate clinical implications because the entire duodenum can be examined endoscopically. In general, most patients with duodenal adenocarcinoma are diagnosed at an advanced stage, resulting in poor prognosis $[3,7,8]$. However, with increasing awareness of the clinical presentation of non-ampullary duodenal tumors, it has been reported that approximately $40-60 \%$ of non-ampullary duodenal tumors are asymptomatic and that most cases are detected during surveillance esophagogastroduodenoscopies or routine medical checkups $[9,10]$. Furthermore, studies from Japan have shown that recent advances in endoscopic treatment provide favorable outcomes during the early stages of non-ampullary duodenal tumors [11-15]. However, since the incidence of non-ampullary duodenal adenocarcinoma is low, it is necessary to recognize its risk factors for effective diagnosis. Moreover, the identification of risk factors would enable risk stratification that can be applied in clinical practice for effective screening, as has been done for other cancers, such as esophageal and gastric cancer [16-18]. Our systematic review summarizes the current evidence from observational studies on the risk factors for non-ampullary duodenal adenocarcinoma.

\section{Methods}

\section{Information Sources and Search Strategy}

This study was performed according to the PRISMA statement [19]. A search of the medical literature published in English and Japanese was conducted using electronic databases, including PubMed, Cochrane Library, Japan Medical Abstracts Society, and Web of Science, from inception to March 2019. Studies that assessed the association between dietary habits, lifestyle behaviors, comorbidities, and duodenal cancer were extracted. The full strings used for bibliographic searches in PubMed, Cochrane Library, Japan Medical Abstracts Society, and Web of Science are reported in Supplementary File 1. This search was supplemented with a literature search of reference lists from potentially eligible articles to find additional studies. The protocol for this systematic review was registered and is available on PROSPERO, an international database of prospectively registered systematic reviews (registration number: CRD42020142009).

\section{Eligibility Criteria}

Studies fulfilling the following eligibility criteria were selected for analysis: (1) prospective or retrospective studies that enrolled patients $\geq 20$ years old diagnosed with non-ampullary duodenal adenocarcinoma and (2) the association between dietary habits, lifestyle behaviors, comorbidities, and non-ampullary duodenal adenocarcinoma were assessed. Studies reported solely as abstracts, editorials, and case reports as well as those investigating only other duodenal malignancies (such as ampullary adenocarcinoma, neuroendocrine tumor, lymphoma, gastrointestinal stromal tumor, etc.) were not included. In cases of multiple publications from the same cohort, the most recent data were analyzed.

\section{Data Collection}

First, titles and abstracts of the articles identified by the search strategy were independently screened. Next, full texts of potentially relevant publications were retrieved and assessed. This screening was independently performed by any two of the three investigators (Y.Y., M.Y., and N.K.). Any discrepancies were resolved by the third investigator. The following data were extracted from included studies: name of the first author, publication year, study design, country where the study was conducted, sample size, and risk factors. For each risk factor, the corresponding measure of effect (odds ratio or hazard ratio according to the specific design of the study) was extracted. When the measure of effect was not described, it was calculated as accurately as possible from the number of occurrences of duodenal cancer described.

\section{Quality Assessment}

The Newcastle-Ottawa Scale (NOS) for non-randomized studies was used to assess the risk of bias in individual studies [20]. The NOS specific to cohort and case-control designs was used, with an overall quality score ranging from 0 (minimum) to 9 (maximum).

We also used the transparent and systematic Grading of Recommendations, Assessment, Development, and Evaluations framework to rate the quality of evidence across studies included in this review [21]. The Grading of Recommendations, Assessment, Development, and Evaluations approach assesses the quality of a body of evidence as high, moderate, low, or very low based on the following parameters: study design (randomized or observational), risk of bias, inconsistency, indirectness, imprecision, publication bias, effect size, dose-response, and all plausible residual confounding. Discrepancies in the quality assessment were discussed and resolved by all 3 authors (Y.Y., M.Y., and N.K.).

\section{Results}

\section{Studies Included in the Review}

A total of 1,265 articles were retrieved from the online databases. After the removal of 21 duplicate articles, we conducted an initial screening and excluded 1,244 articles after reviewing titles and abstracts. We then retrieved the full texts of the remaining 31 articles that were considered to be potentially eligible for inclusion; after further review, 23 articles were excluded. We found 2 additional 


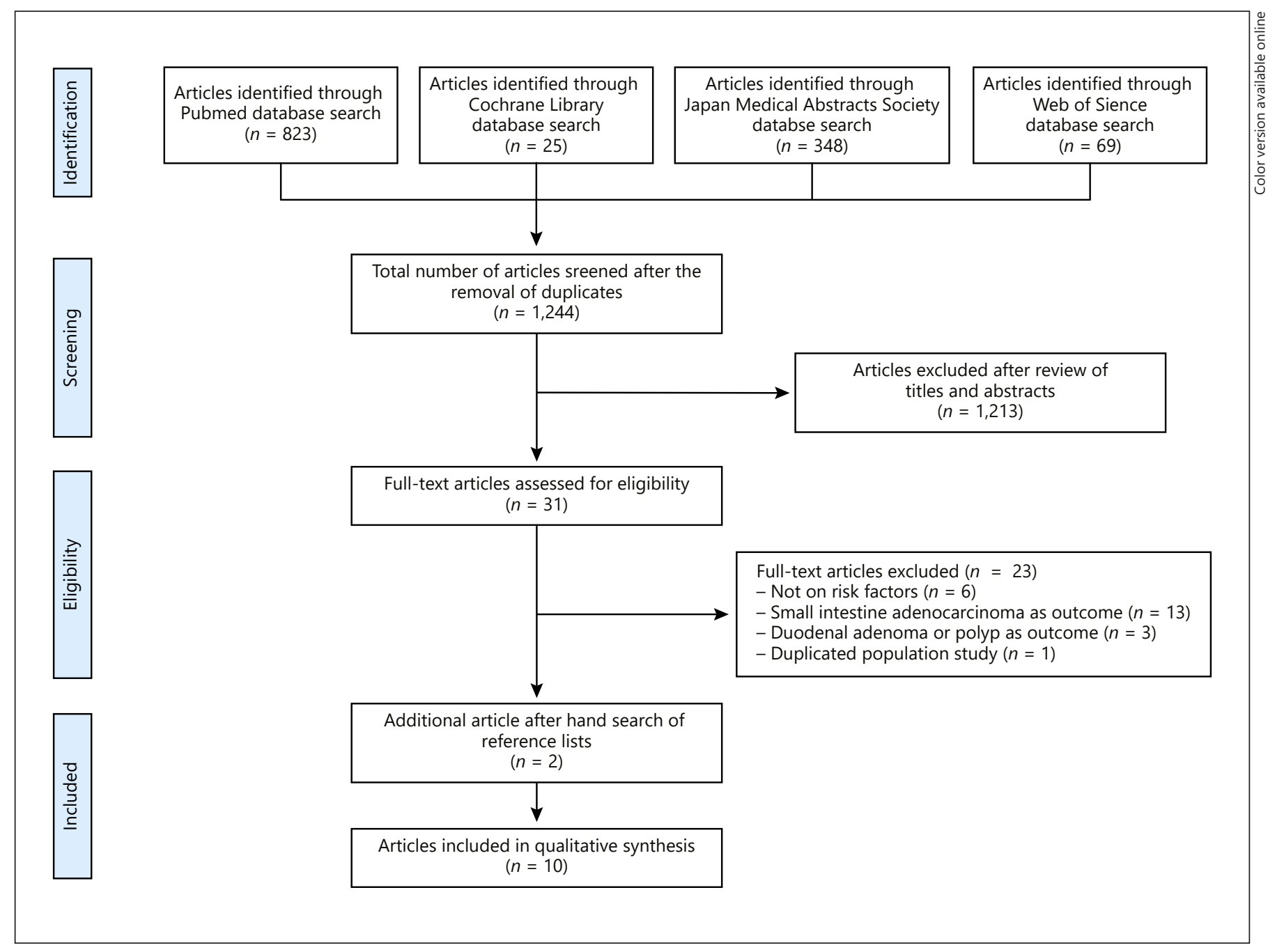

Fig. 1. Selection process of articles included in this systematic review.

Table 1. Characteristics of the five studies on the general population

\begin{tabular}{|c|c|c|c|c|c|c|}
\hline Author & Year & Study design & Country & $\begin{array}{l}\text { Distinguished between } \\
\text { ampullary and non- } \\
\text { ampullary cancers }\end{array}$ & Number of participants & $\begin{array}{l}\text { NOS } \\
\text { quality } \\
\text { score }\end{array}$ \\
\hline $\begin{array}{l}\text { Matsuzaki } \\
\text { et al. [24] }\end{array}$ & 2019 & Case-control & Japan & Yes & $\begin{array}{l}\text { Cases, } n=157 \\
\text { Controls, } n=314\end{array}$ & 6 \\
\hline $\begin{array}{l}\text { Kakushima } \\
\text { et al. [25] }\end{array}$ & 2017 & Case-control & Japan & Yes & $\begin{array}{l}\text { Cases, } n=156 \\
\text { Controls, } n=468\end{array}$ & 7 \\
\hline $\begin{array}{l}\text { Schatzkin } \\
\text { et al. [22] }\end{array}$ & 2008 & Prospective cohort & USA & Yes & $\begin{array}{l}\text { Cohort of } 492,321 \text { participants; } \\
51 \text { cases observed during an average of } 7 \text { years }\end{array}$ & 9 \\
\hline $\begin{array}{l}\text { Bjorge } \\
\text { et al. [23] }\end{array}$ & 2005 & Prospective cohort & Norway & Yes & $\begin{array}{l}\text { Cohort of 2,001,624 participants; } 230 \text { cases observed } \\
\text { during an average of } 23 \text { years }\end{array}$ & 9 \\
\hline $\begin{array}{l}\text { Wang } \\
\text { et al. [26] }\end{array}$ & 2003 & Case-control & China & Unknown & $\begin{array}{l}\text { Cases, } n=101 \\
\text { Controls, } n=310\end{array}$ & 3 \\
\hline
\end{tabular}

NOS, Newcastle-Ottawa Scale.

Risk Factors for Duodenal Adenocarcinoma 
Table 2. Risk factors for non-ampullary duodenal adenocarcinoma in the general population

\begin{tabular}{|c|c|c|c|c|}
\hline Height & $1[23]$ & & $\begin{array}{l}\text { Men } \\
170-179 \mathrm{~cm} \text { reference } \\
160-169 \mathrm{~cm} 0.99(0.60-1.61) \\
180 \mathrm{~cm} 1.04(0.69-1.62) \\
\text { Women } \\
160-169 \mathrm{~cm} \text { reference } \\
150-159 \mathrm{~cm} 0.94(0.62-1.44) \\
170 \mathrm{~cm} 1.33(0.74-2.39)\end{array}$ & Very low \\
\hline Fiber from grains (per $5 \mathrm{~g} / \mathrm{d}$ ) & $1[22]$ & & $0.78(0.31-1.42)$ & Very low \\
\hline Fiber from fruits (per $5 \mathrm{~g} / \mathrm{d}$ ) & $1[22]$ & & $0.75(0.43-1.30)$ & Very low \\
\hline Fiber from vegetables (per $5 \mathrm{~g} / \mathrm{d}$ ) & $1[22]$ & & $0.87(0.64-1.20)$ & Very low \\
\hline Fiber from beans (per $2 \mathrm{~g} / \mathrm{d}$ ) & $1[22]$ & & $0.72(0.48-1.08)$ & Very low \\
\hline Whole grains (per 1 serving/1,000 kcal) & $1[22]$ & & $1.04(0.52-2.09)$ & Very low \\
\hline Smoking & $2[24,25]$ & $\begin{array}{l}\text { [24] Not significant } \\
{[25] 2.71(1.96-3.73)}\end{array}$ & & Very low \\
\hline Helicobacter pylori & $2[25,26]$ & $\begin{array}{l}{[25] 1.84(1.28-2.63)} \\
{[26] 5.60(3.12-10.55)}\end{array}$ & & Very low \\
\hline Gastric cancer & $1[24]$ & Not significant & & Very low \\
\hline Colorectal cancer & $2[24,25]$ & $\begin{array}{l}\text { [24] Not significant } \\
\text { [25] } 3.74(1.74-7.99)\end{array}$ & & Very low \\
\hline Short-segment Barrett's esophagus & $1[24]$ & $9.05(1.65-49.5)$ & & Very low \\
\hline Fundic gland polyps & $1[24]$ & $4.68(1.44-15.2)$ & & Very low \\
\hline Gastric atrophy & $2[24,25]$ & $\begin{array}{l}\text { [23] Not significant } \\
{[24] 0.95(0.63-1.83)}\end{array}$ & & Very low \\
\hline
\end{tabular}

OR, odds ratio; CI, confidence interval; RR, relative risk; GRADE, Grading of Recommendations, Assessment, Development, and Evaluations. 
Table 3. Characteristics of the 5 studies on patients with FAP

\begin{tabular}{|c|c|c|c|c|c|c|}
\hline Author & Year & Study design & Country & $\begin{array}{l}\text { Distinguished } \\
\text { between ampullary } \\
\text { and nonampullary } \\
\text { adenocarcinomas }\end{array}$ & Participants, $n$ & $\begin{array}{l}\text { NOS } \\
\text { quality } \\
\text { score }\end{array}$ \\
\hline $\begin{array}{l}\text { Thiruvengadam } \\
\text { et al. [29] }\end{array}$ & 2019 & Case-control & USA & Yes & $\begin{array}{l}\text { Cases }(n=9) \\
\text { Controls }(n=85)\end{array}$ & 6 \\
\hline $\begin{array}{l}\text { Yamaguchi } \\
\text { et al. [28] }\end{array}$ & 2016 & Retrospective cohort & Japan & Unknown & Cohort of 303 FAP patients; cases $(n=7)$ & 4 \\
\hline $\begin{array}{l}\text { Bulow } \\
\text { et al. [30] }\end{array}$ & 2012 & Prospective cohort & $\begin{array}{l}\text { Nordic countries } \\
\text { Netherlands }\end{array}$ & No & $\begin{array}{l}\text { Cohort of } 261 \text { FAP patients } \\
20 \text { cases observed during a median follow-up of } 14 \mathrm{yr}\end{array}$ & 6 \\
\hline $\begin{array}{l}\text { Groves } \\
\text { et al. [31] }\end{array}$ & 2002 & Prospective cohort & UK & No & $\begin{array}{l}\text { Cohort of } 114 \text { FAP patients } \\
6 \text { cases observed during a median follow-up of } 6 \mathrm{yr}\end{array}$ & 7 \\
\hline $\begin{array}{l}\text { Offerhaus } \\
\text { et al. [27] }\end{array}$ & 1992 & Retrospective cohort & USA & Yes & $\begin{array}{l}\text { Cohort of } 1391 \text { FAP patients } \\
7 \text { cases observed for } 18,679 \text { person-years }\end{array}$ & 7 \\
\hline
\end{tabular}

FAP, familial adenomatous polyposis; NOS, Newcastle-Ottawa Scale.

articles that were eligible for inclusion after a manual search of reference lists. Finally, 10 articles were selected for qualitative synthesis. This selection process is summarized in Figure 1.

\section{Characteristics of the Studies}

Of the 10 studies selected for analysis, 4 (40\%) were case-control studies and $6(60 \%)$ were cohort studies. Four of the cohort studies were prospective and 2 were retrospective in nature. Half of the studies were on the general population and the other half was on patients with familial adenomatous polyposis (FAP). Five studies (50\%) clearly distinguished between ampullary and nonampullary cancers, but the others did not report this distinction. Except for one study, all papers were published from 2002 onward.

\section{Quality Assessment}

The median quality score of the studies using the NOS was 6.5 (range 3.0-9.0). The median quality score of the cohort studies was 7.0, whereas that of the case-control studies was 5.5.

\section{Risk Factors for Non-Ampullary Duodenal}

\section{Adenocarcinoma in the General Population}

There were 2 cohort studies and 3 case-control studies on the risk of non-ampullary duodenal adenocarcinoma in the general population (Table 1 ). In the 2 cohort studies, dietary fiber, whole-grain consumption, height, and body mass index were not significantly associated with duodenal cancer $[22,23]$. In the 3 case-control studies, smoking, history of colorectal cancer, Helicobacter pylori positivity, Barrett's esophagus, and fundic gland polyps were reported to be individual risk factors for non-ampullary duodenal adenocarcinoma [24-26]. However, there was no consistent risk factor among these 5 studies, except for $H$. pylori positivity that was considered a risk factor in 2 studies. However, the quality of evidence was considered very low because of the high risk of bias ( $\mathrm{Ta}$ ble 2).

\section{Risk Factors for Non-Ampullary Duodenal}

Adenocarcinoma in Patients with FAP

In patients with FAP, there were 4 cohort studies and one case-control study regarding the risk of non-ampullary duodenal adenocarcinoma (Table 3). Patients with FAP showed a significantly increased relative risk (RR) of non-ampullary duodenal adenocarcinoma (RR, 330.82) [27]. Duodenal adenocarcinoma was significantly frequent in FAP patients with duodenal adenoma [28]. The incidence of non-ampullary duodenal adenocarcinoma increased in patients with Spigelman stage IV at the initial endoscopy, and this finding was consistently reported in 3 studies [29-31]. The Spigelman stage components associated with non-ampullary duodenal adenocarcinoma included polyp size $>10 \mathrm{~mm}$ and high-grade dysplasia (Table 4) [29]. 
Table 4. Risk factors for non-ampullary duodenal adenocarcinoma in patients with FAP

\begin{tabular}{|c|c|c|c|c|}
\hline Risk factor & $\begin{array}{l}\text { Studies [Ref.], } \\
n\end{array}$ & \multicolumn{2}{|l|}{ Effect size } & $\begin{array}{l}\text { GRADE level } \\
\text { of evidence }\end{array}$ \\
\hline Duodenal adenoma & $1[28]$ & $14.18(1.67-662.58)$ & & Low \\
\hline Spigelman stage IV & $3[29,30,31]$ & [29] $10.65(1.99-74.22)$ & $\begin{array}{l}{[30] 6.38(2.68-15.21)} \\
{[31] 18.73(3.86-90.87)}\end{array}$ & Moderate \\
\hline \multicolumn{5}{|l|}{ Tubulovillous or villous histology within } \\
\hline duodenal polyps & $1[29]$ & $2.57(0.51-16.93)$ & & Very low \\
\hline High-grade dysplasia within duodenal polyps & $1[29]$ & $12.10(1.83-80.99)$ & & Low \\
\hline
\end{tabular}

GRADE, Grading of Recommendations, Assessment, Development, and Evaluations; FAP, familial adenomatous polyposis; OR, odds ratio; $\mathrm{CI}$, confidence interval; $\mathrm{RR}$, relative risk.

\section{Discussion}

To the best of our knowledge, this is the first systematic review summarizing the current evidence on the risk factors for non-ampullary duodenal adenocarcinoma. This was a qualitative synthesis as the limited and heterogenous evidence did not support quantitative analysis. No conclusive risk factors were identified for non-ampullary duodenal adenocarcinoma in the general population. However, in patients with FAP, Spigelman stage IV was identified as a consistent risk factor.

H. pylori positivity was the only consistent risk factor in 2 studies on the general population; however, the risk of bias was high in both studies. Moreover, it has been reported that gastric atrophy and gastric cancer, which are associated with $H$. pylori infection, have no significant association with duodenal adenocarcinoma [32]. In addition, Barrett's esophagus and fundic gland polyps, which are inversely associated with $H$. pylori infection $[33,34]$, were reported to be risk factors for duodenal adenocarcinoma [32]. Considering these conflicting results, no definitive conclusion could be reached on whether $H$. $p y$ lori positivity was a risk factor of non-ampullary duodenal adenocarcinoma or not.

Similarly, other factors, such as dietary fiber, wholegrain consumption, height, body mass index, smoking, drinking, dyslipidemia, diabetes, benign gallbladder disease, reflux esophagitis, and colorectal cancer, were not consistently assessed in these individual studies; hence, no definitive conclusions could be reached on whether or not they could be risk factors for non-ampullary duodenal adenocarcinoma. Due to the rarity of the disease and the lack of definitive risk factors, endoscopic screening should not be performed specifically for non-ampullary duodenal adenocarcinoma. However, it is reasonable to evaluate the duodenum during screening or surveillance endoscopy for gastric cancer or esophageal cancer. Reviews of small intestinal cancer, including duodenal cancer, have reported an association between that particular malignancy and risk factors such as smoking, drinking, Crohn's disease, peptic ulcer, and cholecystectomy [2, 35]. Future studies should focus on these factors to elucidate whether or not they are associated with non-ampullary duodenal adenocarcinoma.

Recently, clinicopathological differences of non-ampullary duodenal tumors depending on the location in the duodenum were reported: non-ampullary duodenal tumors on the oral side of the papilla of Vater were more likely to show a gastric phenotype [36], which was associated with a mutation in the GNAS gene [37] and malignant potential [38] and to be invasive carcinomas [39]. These findings suggest that the pathogenesis might differ between non-ampullary duodenal tumors in the proximal and distal duodenum [40]. Thus, risk factors for nonampullary duodenal adenocarcinomas may vary according to the location on the duodenum, and further research is required.

In patients with FAP, the duodenum is second to the colorectum as a site of malignancy [41]. However, little information was available on formal risk assessment for duodenal cancer. Only one article using data from the Surveillance, Epidemiology, and End Results program reported that the RR of duodenal adenocarcinoma was 330.82 [27]. Although only a single observational study 
was found, the level of evidence was judged as moderate because of its very large effect size. The adenoma-carcinoma sequence similar to colorectal cancer is associated with duodenal tumors in patients with FAP. Therefore, duodenal adenoma is a risk factor for duodenal adenocarcinoma, and a clinicopathological classification of duodenal adenomas exists, which is called the Spigelman classification [32]. Using this classification, malignant transformation has been shown in 33-36\% of patients with Spigelman stage IV [30, 31]. Compared to stages 0-III, stage IV was associated with a higher risk for duodenal adenocarcinoma, which was consistent in several studies. Therefore, assessment of an indication for surgery or intensive surveillance is recommended for patients with Spigelman stage IV [42]. Recent data suggest that polyp size and the presence of high-grade dysplasia, that are components of Spigelman stage IV, are the most important predictors of cancer risk [28], supporting the simpler form of the Spigelman classification proposed by the National Comprehensive Cancer Network Guidelines (Genetic/Familial High-Risk Assessment: Colorectal Version 3.2017). However, there are no prospective studies on the validity of surveillance or treatment based on this staging system, and this issue needs to be addressed in the future.

This systematic review has some limitations. First, as non-ampullary duodenal adenocarcinoma is a relatively rare disease, the number of studies analyzing the risk factors for this disease alone was limited. For example, carcinoids were included in the definition of duodenal cancers in 2 prospective cohort studies, although adenocarcinoma was reported to account for the majority of malignant tumors in the duodenum $[5,35]$. There were also several studies on FAP that did not distinguish between ampullary and non-ampullary duodenal adenocarcinoma $[30,31]$. In one case-control study, duodenal adenomas were included as target lesions [24]; however, only data on risk factors associated with adenocarcinoma were extracted for this systematic review. Second, heterogeneity of studies was unavoidable in terms of populations, risk factors analyzed, and statistical methods, including differences in adjusting for confounding variables among studies. Third, most of the risk factors included in this review were assessed as having a very low level of evidence mainly due to study design, risk of bias, and inconsistency. Fourth, the implications of risk factors for non-ampullary duodenal adenocarcinoma were different between the general population and patients with FAP. The adenoma-carcinoma sequence is associated with duodenal tumors in patients with FAP. However, it was reported that in the general population, the adenoma-carcinoma sequence had only limited involvement in the carcinogenesis of sporadic duodenal tumors [43]. In addition, Niwa et al. reported that the pathogenesis might differ between sporadic non-ampullary duodenal adenoma and adenocarcinoma [40]. Therefore, risk factors for the progression from duodenal adenoma to adenocarcinoma were investigated in patients with FAP, whereas risk factors for the incidence of duodenal adenocarcinoma were investigated in the general population.

\section{Conclusions}

There are currently limited data regarding risk factors for non-ampullary duodenal adenocarcinoma, and no conclusive risk factors were identified in the general population. However, in patients with FAP, Spigelman stage IV was identified as a consistent risk factor. Further, better-quality studies investigating risk factors for non-ampullary duodenal adenocarcinoma are needed to improve diagnosis and support effective clinical management of this malignancy.

\section{Statement of Ethics}

An ethics statement was not required for this study type; no human or animal subjects were used.

\section{Conflict of Interest Statement}

Dr. Fujishiro reports personal fees from Olympus, personal fees from Fujifilm, grants and personal fees from Takeda Pharmaceutical, grants and personal fees from EA Pharma, personal fees from Nihon Pharmaceutical, personal fees from Daiichi Sankyo, personal fees from AstraZeneca, grants from HOYA Pentax, grants from Tanabe-Mitsubishi Pharmaceutical, grants from Eisai, grants from Abbvie, grants from Kyorin Pharmaceutical, and grants from Nippon Kayaku, outside the submitted work. Dr. Uraoka reports personal fees from MEDICAL B.B. PARTNERS Co. Ltd., grants and personal fees from 3-D Matrix, Ltd., grants and personal fees from EA Pharma Co., Ltd., personal fees from AstraZeneca K.K., personal fees from DAIICHI SANKYO Co., Ltd., personal fees from AstraZeneca plc, grants and personal fees from Takeda Pharmaceutical Co., grants and personal fees from Janssen Pharmaceutical K.K., grants from Eli Lilly Co., grants and personal fees from Nihon Pharmaceutical Co., personal fees from Boston Scientific Corp, personal fees from FUJIFILM Corporation, personal fees from Otsuka Pharmaceutical Co., Ltd., personal fees from Otsuka Pharmaceutical Factory, personal fees from Mitsubishi Tanabe Pharma Factory Ltd., personal fees from Mylan EPD G.K., personal fees from Ono Pharmaceutical Co., Ltd., personal fees from 
Pfizer Japan Inc., personal fees from Gilead Sciences, Inc., personal fees from Bristol-Myers Squibb, and personal fees from TEIJIN PHARMA Ltd., outside the submitted work. Dr. Kanetaka reports grants from Terumo Corporation, outside the submitted work. Dr. Yabuuchi, Yoshida, Kakushima, Kato, Iguchi, Yamamoto, and Sho have no conflicts of interest to declare.

\section{Funding Sources}

This study was supported by Sciences Research Grant from the Japanese Ministry of Health, Labor, and Welfare.

\section{Author Contributions}

Conceptualization: all authors; design: Y.Y., M.Y., and N.K.; literature search: N.K.; data analysis and interpretation: Y.Y., M.Y., and N.K.; writing - original draft preparation: Y.Y.; writing - review and editing: M.Y., N.K.; final approval of the manuscript: all authors.

\section{References}

1 Siegel RL, Miller KD, Jemal A. Cancer treatment and survivorship statistics, 2019. CA Cancer J Clin. 2019 Jan;69(1):363-85.

2 Aparicio T, Zaanan A, Svrcek M, LaurentPuig P, Carrere N, Manfredi S, et al. Small bowel adenocarcinoma: epidemiology, risk factors, diagnosis and treatment. Dig Liver Dis. 2014 Feb;46(2):97-104.

3 Legué LM, Bernards N, Gerritse SL, van Oudheusden TR, de Hingh IH, Creemers GM, et al. Trends in incidence, treatment and survival of small bowel adenocarcinomas between 1999 and 2013: a population-based study in The Netherlands. Acta Oncol. 2016 Sep-Oct; 55(9-10):1183-9.

$4 \mathrm{Lu} \mathrm{Y,} \mathrm{Fröbom} \mathrm{R,} \mathrm{Lagergren} \mathrm{J.} \mathrm{Incidence} \mathrm{pat-}$ terns of small bowel cancer in a populationbased study in Sweden: increase in duodenal adenocarcinoma. Cancer Epidemiol. 2012 Jun;36(3):e158-63.

5 Bilimoria KY, Bentrem DJ, Wayne JD, Ko CY, Bennett CL, Talamonti MS. Small bowel cancer in the United States: changes in epidemiology, treatment, and survival over the last 20 years. Ann Surg. 2009 Jan;249(1):63-71.

6 Yoshida M, Yabuuchi Y, Kakushima N, Kato M, Iguchi M, Yamamoto Y, et al. The incidence of non-ampullary duodenal cancer in Japan: the first analysis of a national cancer registry. J Gastoroenterol Hepatol. 2020 Oct.

7 Bojesen RD, Andersson M, Riis LB, Nielsen $\mathrm{OH}$, Jess T. Incidence of, phenotypes of and survival from small bowel cancer in Denmark, 1994-2010: a population-based study. J Gastroenterol. 2016 Sep;51(9):891-9.

8 Qubaiah O, Devesa SS, Platz CE, Huycke MM, Dores GM. Small intestinal cancer: a population-based study of incidence and survival patterns in the United States, 1992 to 2006. Cancer Epidemiol Biomarkers Prev. 2010 Aug;19(8):1908-18.

9 Sakae H, Kanzaki H, Nasu J, Akimoto Y, Matsueda $\mathrm{K}$, Yoshioka M, et al. The characteristics and outcomes of small bowel adenocarcinoma: a multicentre retrospective observational study. Br J Cancer. 2017 Nov;117(11): 1607-13.
10 Kakushima N, Ono H, Takao T, Kanemoto H, Sasaki K. Method and timing of resection of superficial non-ampullary duodenal epithelial tumors. Dig Endosc. 2014 Apr;26(Suppl 2): 35-40.

11 Hara Y, Goda K, Dobashi A, Ohya TR, Kato $\mathrm{M}$, Sumiyama K, et al. Short- and long-term outcomes of endoscopically treated superficial non-ampullary duodenal epithelial tumors. World J Gastroenterol. 2019 Feb;25(6): 707-18.

12 Yamasaki Y, Uedo N, Takeuchi Y, Higashino K, Hanaoka N, Akasaka T, et al. Underwater endoscopic mucosal resection for superficial nonampullary duodenal adenomas. Endoscopy. 2018 Feb;50(2):154-8.

13 Yahagi N, Kato M, Ochiai Y, Maehata T, Sasaki M, Kiguchi Y, et al. Outcomes of endoscopic resection for superficial duodenal epithelial neoplasia. Gastrointest Endosc. 2018 Oct;88(4):676-82.

14 Tomizawa Y, Ginsberg GG. Clinical outcome of EMR of sporadic, nonampullary, duodenal adenomas: a 10-year retrospective. Gastrointest Endosc. 2018 May;87(5):1270-8.

15 Nonaka S, Oda I, Tada K, Mori G, Sato Y, Abe $S$, et al. Clinical outcome of endoscopic resection for nonampullary duodenal tumors. Endoscopy. 2015 Feb;47(2):129-35.

16 Kaji K, Hashiba A, Uotani C, Yamaguchi Y, Ueno T, Ohno K, et al. Grading of atrophic gastritis is useful for risk stratification in endoscopic screening for gastric cancer. Am J Gastroenterol. 2019 Jan;114(1):71-9.

17 Yokoyama A, Kumagai Y, Yokoyama T, Omori T, Kato H, Igaki H, et al. Health risk appraisal models for mass screening for esophageal and pharyngeal cancer: an endoscopic follow-up study of cancer-free Japanese men. Cancer Epidemiol Biomarkers Prev. 2009 Feb;18(2):651-5.

18 Yokoyama T, Yokoyama A, Kumagai Y, Omori $\mathrm{T}$, Kato $\mathrm{H}$, Igaki $\mathrm{H}$, et al. Health risk appraisal models for mass screening of esophageal cancer in Japanese men. Cancer Epidemiol Biomarkers Prev. 2008 Oct;17(10): 2846-54.
19 Moher D, Liberati A, Tetzlaff J, Altman DG Preferred reporting items for systematic reviews and meta-analyses: the PRISMA statement. BMJ. 2009 Aug;339(4):b2535.

20 Wells GA, Shea B, O'Connell D, Peterson J, Welch V, Losos M, et al. The Newcastle-Ottawa Scale (NOS) for assessing the quality of nonrandomised studies in meta-analyses 2020 Oct 30. Available from: http://www. ohri.ca/programs/clinical_epidemiology/oxford.asp.

21 Balshem $\mathrm{H}$, Helfand M, Schünemann HJ, Oxman AD, Kunz R, Brozek J, et al. GRADE guidelines: 3 . Rating the quality of evidence. J Clin Epidemiol. 2011 Apr;64(4):401-6.

22 Schatzkin A, Park Y, Leitzmann MF, Hollenbeck AR, Cross AJ. Prospective study of dietary fiber, whole grain foods, and small intestinal cancer. Gastroenterology. 2008 Oct; 135(4):1163-7.

23 Bjørge T, Tretli S, Engeland A. Height and body mass index in relation to cancer of the small intestine in two million Norwegian men and women. Br J Cancer. 2005 Oct;93(7):80710.

24 Matsuzaki J, Suzuki H, Shimoda M, Mori H, Fukuhara S, Miyoshi S, et al. Clinical and endoscopic findings to assist the early detection of duodenal adenoma and adenocarcinoma. United European Gastroenterol J. 2019 Mar; 7(2):250-60.

25 Kakushima N, Ono H, Yoshida M, Takizawa $\mathrm{K}$, Tanaka M, Kawata N, et al. Characteristics and risk factors for sporadic non-ampullary duodenal adenocarcinoma. Scand J Gastroenterol. 2017 Nov;52(11):1253-7.

26 Wang KX, Wang XF, Peng JL, Cui YB, Wang J, Li CP. Detection of serum anti-Helicobacter pylori immunoglobulin $\mathrm{G}$ in patients with different digestive malignant tumors. World J Gastroenterol. 2003 Nov;9(11):2501-4.

27 Offerhaus GJ, Giardiello FM, Krush AJ, Booker SV, Tersmette AC, Kelley NC, et al. The risk of upper gastrointestinal cancer in familial adenomatous polyposis. Gastroenterology. 1992 Jun;102(6):1980-2. 
28 Yamaguchi T, Ishida $\mathrm{H}$, Ueno $\mathrm{H}$, Kobayashi $\mathrm{H}$, Hinoi $\mathrm{T}$, Inoue $\mathrm{Y}$, et al. Upper gastrointestinal tumours in Japanese familial adenomatous polyposis patients. Jpn J Clin Oncol. 2016 Apr;46(4):310-5.

29 Thiruvengadam SS, Lopez R, O'Malley M, LaGuardia L, Church JM, Kalady M, et al. Spigelman stage IV duodenal polyposis does not precede most duodenal cancer cases in patients with familial adenomatous polyposis. Gastrointest Endosc. 2019 Feb;89(2):345-54 e2.

30 Bülow S, Christensen IJ, Højen H, Björk J, Elmberg $\mathrm{M}$, Järvinen $\mathrm{H}$, et al. Duodenal surveillance improves the prognosis after duodenal cancer in familial adenomatous polyposis. Colorectal Dis. 2012 Aug;14(8):947-52.

31 Groves CJ, Saunders BP, Spigelman AD, Phillips RK. Duodenal cancer in patients with familial adenomatous polyposis (FAP): results of a 10 year prospective study. Gut. 2002 May; 50(5):636-41.

32 Spigelman AD, Williams CB, Talbot IC Domizio P, Phillips RK. Upper gastrointestinal cancer in patients with familial adenomatous polyposis. Lancet. 1989 Sep;2(8666): 783-5.

33 Notsu T, Adachi K, Mishiro T, Ishimura N, Ishihara S. Fundic gland polyp prevalence according to Helicobacter pylori infection status. J Gastroenterol Hepatol. 2020 Jul;35(7): $1158-62$.
34 Eröss B, Farkas N, Vincze A, Tinusz B, Szapáry L, Garami A, et al. Helicobacter pylori infection reduces the risk of Barrett's esophagus: a meta-analysis and systematic review. Helicobacter. 2018 Aug;23(4):e12504.

35 Neugut AI, Jacobson JS, Suh S, Mukherjee R, Arber N. The epidemiology of cancer of the small bowel. Cancer Epidemiol Biomarkers Prev. 1998 Mar;7(3):243-51.

36 Yoshida M, Shimoda T, Abe M, Kakushima N, Kawata N, Takizawa K, et al. Clinicopathological characteristics of non-ampullary duodenal tumors and their phenotypic classification. Pathol Int. 2019 Jul;69(7):398406.

37 Matsubara A, Ogawa R, Suzuki H, Oda I, Taniguchi H, Kanai Y, et al. Activating GNAS and KRAS mutations in gastric foveolar metaplasia, gastric heterotopia, and adenocarcinoma of the duodenum. Br J Cancer. 2015 Apr; 112(8):1398-404.

38 Minatsuki C, Yamamichi N, Inada KI, Takahashi Y, Sakurai K, Shimamoto T, et al. Expression of gastric markers is associated with malignant potential of nonampullary duodenal adenocarcinoma. Dig Dis Sci. 2018 Oct; 63(10):2617-25.
39 Matsueda K, Kanzaki H, Matsueda K, Nasu J, Yoshioka M, Nakagawa M, et al. The clinicopathological differences of sporadic non-ampullary duodenal epithelial neoplasm depending on tumor location. J Gastroenterol Hepatol. 2019 Sep;34(9):1540-4.

40 Niwa A, Kuwano S, Tomita H, Kimura K, Orihara Y, Kanayama T, et al. The different pathogeneses of sporadic adenoma and adenocarcinoma in non-ampullary lesions of the proximal and distal duodenum. Oncotarget. 2017 Jun;8(25):41078-90.

41 Jagelman DG, DeCosse JJ, Bussey HJ. Upper gastrointestinal cancer in familial adenomatous polyposis. Lancet. 1988 May;1(8595): 1149-51.

42 Ishida H, Yamaguchi T, Tanakaya K, Akagi K, Inoue Y, Kumamoto K, et al. Japanese Society for Cancer of the Colon and Rectum. Japanese Society for Cancer of the Colon and Rectum (JSCCR) Guidelines 2016 for the Clinical Practice of Hereditary Colorectal Cancer (Translated Version). J Anus Rectum Colon. 2018 May;2(Suppl 1):S1-51.

43 Ota R, Sawada T, Tsuyama S, Sasaki Y, Suzuki $\mathrm{H}$, Kaizaki $\mathrm{Y}$, et al. Integrated genetic and epigenetic analysis of cancer-related genes in non-ampullary duodenal adenomas and intramucosal adenocarcinomas. J Pathol. 2020 Nov;252(3):330-42. 